\title{
Effects of Health Insurance Concentration Market on Insurance Coverage in Colombia
}

- Rodríguez Sandra Acosta

\begin{abstract}
This study seeks to contribute to the limited knowledge on the health insurance market in Colombia. Using a database constructed for this purpose, we describe the structure of the health insurance market in Colombia, specifically its two types of insurance, for 33 market areas during the period 2007-2011. Taking as a central concern the role of insurance as a guarantee of access to health services, this study aims to analyze the impact of health insurers' market power on insurance coverage. The principal result verifies the existence of concentrated markets, and insurers have power in those markets in terms of their influence on the level of insurance coverage. This leads to concentrated market structures and thus the exercise of market power by insurers, which constitute potential constraints in access to health services.
\end{abstract}

Keywords: market concentration, market power on access, health insurance, health system, insurance coverage, Colombia.

JEL Classification: D43

\section{INTRODUCTION}

Markets in health care are characterized by multiple imperfections, largely resulting from uncertainty and information asymmetries between buyers and sellers; these imperfections are inherent in the nature of health and medical care (Arrow, 1963; Pauly, 1968; Gaynor \& Vogt, 2000). As a result, social welfare issues must be decided in a second-best context, which has led policy makers to favor strong state intervention through regulation. However, information on health insurance markets operation remains scarce, and public policies have been developed based more on assumptions regarding how these markets are changing and how they respond to regulation (Dafny et al., 2011; Gaynor \& Vogt, 2000).

The main literature in this field concerns the insurance market in the United States, for which empirical evidence, in the form of certain databases and statistical information, has only recently become available. In the case of Latin America, such studies are almost nonexistent due to the absence of reliable information, and ongoing efforts to reform health systems in recent years, such as Colombia.

The recent debate on social security reform and hence health insurance systems (Colombia 1993, 2007, 2011, United States 2009-2010; China 2003) has primarily focused on the consequences of the non-competitive nature of the health insurance industry. Reviews generally come from different medical and hospital associations, in the case of the United States, and user associations and the Comptroller General of the Republic in Colombia, who argue that most metropolitan 
areas are dominated by a few large insurance firms. This may result in non-competitive markets where health insurers exercise market power in their respective product markets (Bates et al., 2010). Despite the public importance of this issue, relatively few empirical studies have examined the relationship between concentration in health insurance markets and the exploitation of market power.

This study seeks to contribute to the limited knowledge on the health insurance market in Colombia. Using a database constructed for this purpose, we describe the structure of the health insurance market in Colombia, specifically its two types of insurance, for 33 market areas during the period 2007-2011. Taking as a central concern the role of insurance as a guarantee of access to health services, this study aims to analyze the impact of health insurers' market power on insurance coverage in Colombia. Following Bates et al. (2010), who diverge from the trend in the recent literature about market power of health insurers. We do not focus on changes in the value of the premium but on insurance coverage, in order to analyze the impact of health insurers' market power on the percentage of insured individuals in different areas of the Colombian market.

The principal result verifies the existence of concentrated markets, and insurers have power in those markets in terms of their influence on the level of insurance coverage. This leads to concentrated market structures and thus the exercise of market power by insurers, which constitute potential constraints in access to health services.

The remainder of this paper is structured as follows: Section 2 describes the health insurance market in Colombia; Section 3 presents the literature review; Section 4 discusses the research methodology and data; Section 5 presents the results of the analysis; and Section 6 presents the conclusions and limitations of the study.

\section{THE INSURANCE MARKET IN COLOMBIA}

The Social Security System in Health -SGSSS- in Colombia aims to provide all individuals, regardless of their financial means, with access to a package of basic services. Following this objective, the system is divided into two insurance regimes: a Contributory Regime (CR), which guarantees access to a compulsory health plan to higher- and middle-income individuals (taxpayers under this regime include labor contract workers, public servants earning over a minimum monthly salary, $€ 318$ in 2011, and their beneficiaries: wife (husband), children under 18, children with disabilities, and students under 25 years old). The second is the Subsidized Regime (SR), which guarantees its members access to a subsidized health plan and focuses on the poor.

The contributory scheme is financed through mandatory contributions applied to members, corresponding to $12.5 \%$ of salary. The employer is responsible for $8.5 \%$, and the employee is responsible for $4 \%$. The contribution is collected by insurance companies, health promoting entities (EPS), which are freely selected by the member. The EPS deducts from each contribution the value of the legally stipulated premium, called the capitation payment unit (UPC), and transfers the difference to a public fund called the Solidarity and Guarantee Fund (Fosyga). The UPC is the premium that the social security system provides to the EPS for each member in exchange for the mandatory package of health services (POS). A percentage of the contribution, 
called a solidarity point, is transferred to regional entities to fund membership in the subsidized regime.

The right to membership in the subsidized regime is determined according to the classification given by the Beneficiary Identification System (Sisben). This system classifies the population into six levels, one of which represents lower socioeconomic status. The population classified in Sisben levels I and II are eligible for the subsidized regime. The subsidized insurance system is managed by the Subsidized Regime Administrators (ARS or EPSS). Members can choose their insurance company, and the insurers receive a premium for each insured individual (UPC-subsidized), corresponding to the estimated value of the services in the package provided by the state under this regime. It is the responsibility of each EPSS to establish agreements with public and private hospitals (IPS), as well as professionals who provide health services to beneficiaries, to support the subsidized health plan (POSS).

The two regimes (agents) created to manage insurance provision are service companies, which can be public, private or mixed, with the basic function of "organizing and guaranteeing, directly or indirectly, the provision of a mandatory health plan to enrollees" (Law 100, art. 177). Thus, the two fundamental variables are regulated by the state: the mandatory health plan (POS), an homogeneous single health plan required to provide the EPS and EPSS to its members and develops the list of services, medicines and procedures covered, and the unit of payment per capita (UPC), which is the price, or premium, that these entities receive to cover the value of POS, including administrative costs. An important difference between these two regimes is that while demand for coverage in the contributory regime, through the EPS, arises because each individual able to pay freely choose an EPS, in the subsidized regime, the demand captured by the EPSS is mediated by a state agent (municipality or health department) that is responsible for signing contracts to enroll poor individuals in an entity.

The rules governing the entry and operation of insurers can be classified, following Arango et al. (2002), according to their content and purpose: technical standards, financial standards, and relationships with users. The first rules are barriers related to the size of the insurer and its composition: EPS were required to have at least 20,000 affiliates in the first year and 50,000 in the second. For EPSS, no limitations were established regarding the composition of its enrolled population in terms of age group or gender. At the beginning EPSS was initially authorized to operate with 5,000 members and 50,000 beginning in the third year; then, in 2001, EPSS was required to certify it ruled that should certify 200,000 members or 50,000, with some limitations on administrative expenses. There are also regulations on capital, solvency margin and the definition of the legal reserve that insurers are required to maintain: the mandatory capital amount for each EPS is 10,000 times the legal monthly minimum wage (SMLV).

The use of exclusions and pre-existing conditions is prohibited under both regimes. With respect to the use of services, members of the contributory scheme must be affiliated with the plan for a minimum of 18 months to receive medical services considered high cost, while no such restrictions exist under the subsidized regime. Law 100 also establishes copayments to regulate the use of services. Under the Act, multiple copayments cannot be applied to a service simultaneously, and should take the member's income into account. 
Finally, the provision of health services is the responsibility of the so-called Health Provider Institutions (IPS), which can be public or private organizations that provide health services. After the reform, the public hospitals began to compete with the private sector in the provision of services. Thus to protect the former, EPSS was required to meet at least $60 \%$ of its demand with public hospitals. Under the CR, Law 100 allows an EPS to provide services directly or contract with provider institutions (IPS), but this is not allowed under the SR. Additionally, an EPS is allowed to create its own IPS, engage in takeovers, mergers and other vertical relationships between insurers and health service providers. In 2007, due to concerns over the trend toward high levels of vertical integration, Act 1122 introduced a limit to integration mandating that an EPS cannot use its own IPS for any more than $30 \%$ of health expenditures.

Vasquez and Gómez (2004), in a quantitative and qualitative study for the insurance market in Colombia, identified that the profile of members within each EPS may have similar characteristics in terms of: type of work, type of membership, age, gender, high-cost diseases and geographic location, which may be due to a self-selection problem; or the establishment of market niches by insurance companies. Following the second argument, one of the most recent studies on the insurance market in Colombia, conducted by the Superintendence of Industry and Commerce, emphasizes the EPSs' differential participation in different segments of the population and explains that these differences may be a signal of risk selection practices by some insurers (Superintendence of Industry and Commerce, 2012).

\section{LITERATURE REVIEW}

When analyzing competition in health care markets and specifically among insurers, researchers and regulators recognize that insurers compete for customers within local geographic markets. The most recent trend in these studies has been to investigate how concentrated insurers are, the extent to which this concentration is desirable, and to measure the degree to which such concentration results in market power.

Several studies published in the health economics or health services literature examine the relationship between the structure of the insurance industry and an outcome variable, which is usually the price (or premium). A review by Scanlon et al. (2006) found 35 studies in the period 1994-2004 investigating the impact of competition among health insurers on health care outcomes. Of these, seven consider some measure of the premium as the outcome of interest. Most find a negative association between competition and the premium. However, these studies face significant problems related to the data quality, and none of them address the potential endogeneity of the measure of competition employed.

Gaynor and Town (2011) recognize a change in this trend and note that the last ten years have witnessed a growing use of methods that originate in industrial organization studies. It has only recently become possible to find papers that address the issue of competition among insurance firms, although these primarily address the U.S. market (Dranove et al., 2003, Town \& Liu, 2003; Maestas et al., 2009; Lustig, 2010 and Starc, 2010) and specifically insurance markets in Switzerland and the Netherlands in Frank \& Lamiraud (2009) and Bolhaar et al. (2010), respectively. 
The three most recent and outstanding works in this area are Dafny (2008), Dafny (2010) and Dafny et al. (2011b). Dafny (2008), explores the competitive behavior in local geographic markets in the United States, for the period 1998-2005. The author provides evidence of direct price discrimination by more profitable firms, suggesting that health insurers possess and exercise market power in at least one market.

Dafny (2010), uses a model of negotiation between insurers and employers. Specifically, the paper investigates whether firms with high profits pay higher insurance premiums, controlling for differences in selected plans, working populations and market conditions. The author finds that firms with positive profit shocks face large premium increases, even for the same health plan. This increase is higher in markets with fewer insurers (particularly six or fewer).

In Dafny et al. (2011b), follow the approach of the Structure Conduct Performance paradigm using the same data set as Dafny (2008). In this case, they examine how the rate of insurance premium growth is affected by the degree of concentration in the insurance market, as measured by the Herfindahl-Hirschman concentration index (HHI). Specifically, they analyze the 1999 merger of the insurers Aetna and Prudential Health Care. The authors exploit the differential impact of the merger in different local markets to estimate the causal effect of this concentration on market-level premiums. They find that the merger led to a nearly two percentage point increase in premiums during the study period.

The only works that regard the premium-concentration relationship differently, and are of particular interest to this research, are those of Bates et al. (2010) and Pauly et al. (2002). The first employs panel data from 50 states and the District of Columbia in the United States for the period 2001-2007 and examines how market concentration in health insurance at the state level influences the percentage of population with individually purchased private health insurance or employer-sponsored coverage. The results suggest that health insurers possess and exercise market power. Specifically, the results indicate that an increase in the HHI reduces membership in the individually purchased insurance segment.

Pauly et al. (2002) studied the relationship between the levels of competition in the insurance market in the United States between 1994 and 1997, and the profitability enjoyed by the insurance companies. The authors seek to verify that insurers with lower profitability are in more competitive markets and thereby determine whether competition drives down unusually high profits over time. They found that the profits were significantly lower on average in 1994 in more competitive markets, measured by using the number of HMOs or HHI. Moreover, those markets with higher returns were not able to maintain their relative position in 1997.

\section{METHODOLOGY AND DATA}

\subsection{Sample and data sources}

The data used in this analysis consist of 165 observations from a five-year panel constructed using different sources (National Department of Statistics, DANE, Ministry of Social Protection and Solidarity and Guarantee Fund, Fosyga). Each observation represents a geographical area (Department), and hence the unit of analysis will be 33 geographical market areas over five years. 
The data on the socio-demographic characteristics of the 33 market areas used in the regression include the period 2007-2011, and the variables are as follows:

- A proxy for per-capita income: regional per capita GDP (measured in 2007 dollars).

- Total population: total population by market area.

- Children: proportion of children in a market area, calculated as those under five years of age.

- Elderly: the population over 55 years, age range taken from the national policy on aging and old age, 2007-2009, from the Ministry of Social Protection.

- Higher education coverage: proportion of the population having completed higher education.

The data on the insurance market include the enrollment information and number of insurers in the contributory regime (CR) and the subsidized regime (SR) for the 33 market areas used in the regression during 2007-2011. The coverage ratio was estimated using as reference the potential population of each regime. Thus, to calculate the potential of SR, I used the population, classified as SISBEN 1 and 2, plus the indigenous population, less the population in the SISBEN 1 and 2 covered with CR. And the potential population for the contributory regime was calculated as the difference between the total population and the potential of the subsidized regime. The variables are:

- Affiliated with the CR: total active population in the contributory regime, including contributors and beneficiaries. Information available through the Solidarity and Guarantee Fund (Fosyga), Badua membership records published in December of each year. This variable is used to determine the coverage percentage of the contributory regime in each market area, as a proportion of the population enrolled in the CR compared to the potential population of the market area for each year.

- Affiliated with the SR: total active population in the subsidized regime, including the head of household and his (her) beneficiaries. Information available through Fosyga, Source Badua records published in December of each year. This variable is used to determine the percentage of subsidized coverage, as the proportion of the population enrolled in the subsidized regime compared to the potential population of the market area.

- Number of EPS: total insurers (in CR and SR).

\subsection{Empirical model}

The restriction of product availability forms the basis of the reduced form model of the health insurance product $(\mathrm{Q})$ that will address the objective of this work. Specifically, the small number of firms is captured by the Hirschman-Herfindahl Index (HHI), under the assumption of barriers to entry, and X represents various conditions of market supply and demand.

$Q_{j t}^{R}=f\left(H H I_{j, t-1}^{R} ; X_{j, t-1}\right)$ 
The $H H I^{\mathrm{R}}{ }_{j}$ is the Hirschman-Herfindahl index of concentration in market area $j$, with $\mathrm{R}=$ affiliate scheme, contributory or subsidized. This index reflects both the number of insurance providers in the market area and the distribution of market shares across insurers. The index is constructed by adding and weighting the squares of the market shares of all insurers within a market area.

An important methodological consideration when studying the effect of the concentration of health insurers on insurance coverage under their respective regimes is that this relationship cannot be estimated using the technique of ordinary least squares (OLS) due to the potential endogeneity of the measure used to consider the market structure (HHI). First, the concentration of the EPS and coverage are correlated. The decision to enter or remain in a specific geographic market may be affected by the level of coverage in that area, as the insurers would tend to locate in less concentrated markets where there is the potential to compete, or in markets where there are potential competitors.

Another source of endogeneity for this measure concerns the simultaneity between the concentration of insurers and the number of persons insured, where an increase in the concentration of insurance is a positive function of the number of members. Third, the HHI can be correlated with unobservable market characteristics that may influence the level of affiliation. As a result, the variable that controls for market structure, HHI, could be correlated with the error term and would be endogenous. It could also be correlated with unobservable characteristics that influence the demand for health insurance. This would lead to the selection of insurers by individuals in a nonrandom way (McLaughlin, 1987, McLaughlin et al., 1984). Thus the high costs associated with insurance may be the result of selection bias where high-risk individuals (the elderly, children, pregnant women, un-healthy individuals, for example) are affiliated with the insurer.

To correct for the potential endogeneity of the concentration measure, the estimation method employed here is two-stage least squares (2SLS). The advantage of this method is that identifying the appropriate controls (instruments) to correct for endogeneity leads to unbiased estimators.

As the quality of the 2SLS estimate depends on the quality of the instruments used, we follow the recommendations of Murray and College (2010), the proposal of Staiger and Stock (1997) and the critical values of Stock and Yogo (2002) to detect weak instruments; moreover, we performed sub-identification and redundancy tests using Kleinbergen-Paap statistical tools.

Additionally, after determining the proper model for the analysis, we apply a robust Hausman test and the Sargan-Hansen test to determine whether fixed or random effects are the most appropriate. The test result indicates that an analysis of the reduced form equation by 2SLS for panel data with a fixed effects model is more appropriate.

The overall model is:

Model I: $Q_{j t}^{R}=\beta_{0}+\beta_{1} H H I_{j t-1}^{R}+\beta_{2} X_{j t-1}+\varphi_{j} v_{j}+\delta_{t} T_{t}+\epsilon_{j t}$

Where: $Q^{\mathrm{R}}{ }_{j t}$ is membership coverage in market area $j(\mathrm{j}=1, \ldots, 33)$ in period $\mathrm{t}(\mathrm{t}=2007, \ldots, 2011)$ under regime $\mathrm{R}(\mathrm{R}=\mathrm{CR}$ or $\mathrm{SR}) ; X_{j t}$ is a vector of characteristics of the market area over time (control variables); $H H I^{R}{ }_{j t}$ is a measure of market structure in a market area over time. The term $v_{j}$ is the effect of unobserved individual heterogeneity that does not change over time; $T$ is a time 
fixed effect, and $\epsilon_{j t}$, is the usual error term including unobserved variables or effects that change over time. Following Dafny et al. (2011b), we include lags of the explanatory variables to reflect that insurers act prospectively by taking into account the premiums collected each period to define the level of insurance (Dafny et al., 2011b; Bates et al., 2010).

If there is an inverse relationship between the HHI indicator and Q, these behaviors suggest market power. That is, high market concentration will result in a restriction of the market product, health insurance. Conversely, if there is a positive relationship between these two variables, this could be indicative of efficiency associated with larger firm size (Demsetz, 1973).

\subsubsection{Defining market area}

In the specific case of health services, for example, the two market dimensions are the product market and the geographic market. The first typically refers to the proximity to the patient and the second to the traditional socio-political division. For the analysis of insurance and health care, geographic proximity is most frequently employed; hence it tends to identify the geographic area around which some measure is defined. In the U.S., counties are treated as the geographical market of interest (Baker and Corts, 1996; Dranove et al., 2003 and Schneider et al., 2008). Other studies such as Kopit (2004) and Pauly et al. (2002), among others, employ the Metropolitan Statistical Areas (or MSA) as the relevant geographic market.

The Colombian territory is divided in administrative and political provinces called departments, which are used to identify cultural and economic characteristics, governmental programs and budget definition. This study considers the department level as the geographic market, which was the most disaggregated level available in the data. As this is the first investigation of its kind in Colombia, there are no baseline studies that define market areas in a manner other than that proposed here. Future studies should verify whether the predictions obtained in this study persist when considering, for example, metropolitan areas and cities.

\subsubsection{Instrumental Variables}

According to Evans et al. (1993), Bos (2004) and Bates et al. (2010), among others, a lagged index of market concentration represents a good instrument. Murray (2006), highlights the choice of the lag order: Some analysts use long lags of instruments, under the notion that higher-order lags can reduce the correlation between the instrument and the disturbance in an OLS regression; however, a longer lag length is more likely to be weakly correlated with the suspected endogenous variable.

Given this dilemma, HHI values with one and two-year lags are specified (and evaluated) as instruments in the various models. The prediction would be that larger market areas would lead to more insurers and lower concentration than smaller market areas (Pauly et al. 2002; Lamiraud \& Frank, 2009). Thus, according to Pauly et al. (2002) market size and the number of physicians per 100,000 inhabitants are included (and evaluated) as potential instruments to predict market concentration.

As the quality of the 2SLS estimates depends on the quality of the instruments employed, we applied the rule of thumb proposed by Staiger and Stock (1997) and the critical values in Stock 
and Yogo (2002) to detect weak instruments. Additionally, we used the sub-identification and redundancy of instruments (statistical Kleinbergen-Paap) tests.

Some general statistical data are presented in Table 1.

Tab. 1 - Descriptive statistics for the average of the period 2007-2011. Source: National Department of Statistics, DANE, Ministry of Social Protection and Solidarity and Guarantee Fund, Fosyga.

\begin{tabular}{|l|c|c|c|}
\hline Variable & Obs & Mean & Std. Dev. \\
\hline HHI-CR & 165 & 3231.9 & 1803.8 \\
\hline Coverage CR & 165 & 58 & 25.82 \\
\hline HHI-SR & 165 & 2752.9 & 1751.78 \\
\hline Coverage SR & 165 & 90 & 28.72 \\
\hline Proportion of population with higher education (college) & 165 & 25.83 & 14.00 \\
\hline Proportion of elderly people & 165 & 12.39 & 3.06 \\
\hline GDP per-capita & 165 & 3215.27 & 1879.27 \\
\hline Hospital Level I & 165 & 2.44 & 1.52 \\
\hline Hospital Level II & 165 & 0.66 & 0.58 \\
\hline Total population & 165 & 1366429 & 1610369 \\
\hline Number of doctors & 164 & 90.10 & 48.98 \\
\hline Proportion of children & 165 & 21.81 & 3.83 \\
\hline Market penetration CR & 165 & 3.206 & 0.691 \\
\hline Market penetration SR & 165 & 4.067 & 0.303 \\
\hline Number of insurers CR & 165 & 2.830 & 0.302 \\
\hline Number of insurers SR & 165 & 2.048 & 0.542 \\
\hline
\end{tabular}

Note: CR, contributive regime; SR, subsidized regime; HHI, Hirschman-Herfindahl concentration index.

\section{RESULTS}

Before 1995, insurance coverage in Colombia was less than $10 \%$; with the implementation of the social security reform, coverage increased to more than triple next year, which was considered a dramatic effect of the reform. However, even after more than fifteen years, the contributory scheme coverage does not exceed $60 \%$. That is even if membership is compulsory a part of the eligible population remains uninsured. What has been identified by the "Defensoría del Pueblo", is that the insurance companies refuse membership on the grounds that the applicant for membership does not meet the income profile that guarantees payment of the premium (f.i., self-employed or micro-entrepreneur) and leaves no option to the citizen more than legal proceedings and claims; which, given the regulatory weakness of the Colombian health system and up being lengthy legal processes that discourage affiliation.

The average HHI for the period between 2007 and 2011 was 3,230 for the CR, with a minimum of 1,057 and a maximum of 8,144. The corresponding figures for the SR were an average of 2,753 
with 943 and 8,758 being the minimum and maximum HHI values, respectively. This indicates that the markets under both regimes appear, on average, fairly concentrated when compared to the 1800 threshold proposed by the U.S. Federal Trade Commission and Department of Justice. The figure 1 highlights the market areas where the HHI values are below that threshold. According to this indicator, for the entire period under the CR, 25\% (8) of the market areas, on average, were not concentrated, while in 2007 and 2010, 27\% and 30\%, respectively, were not concentrated; in 2011, the percentage fell to $21 \%$.

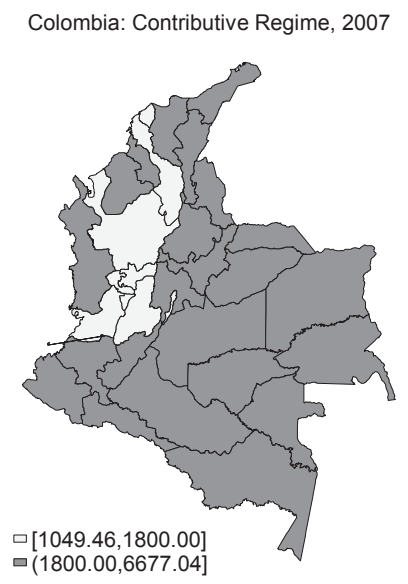

Colombia: Subsidized Regime, 2007

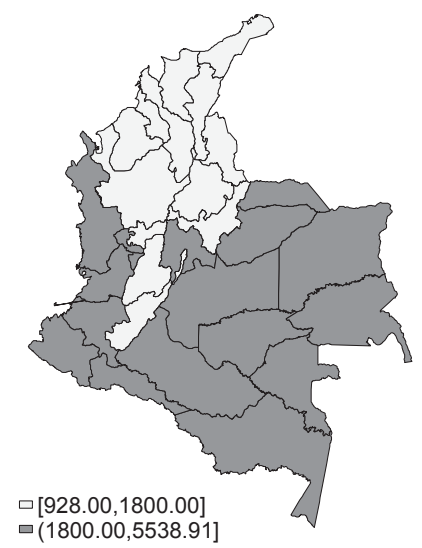

Colombia: Contributive Regime, 2011

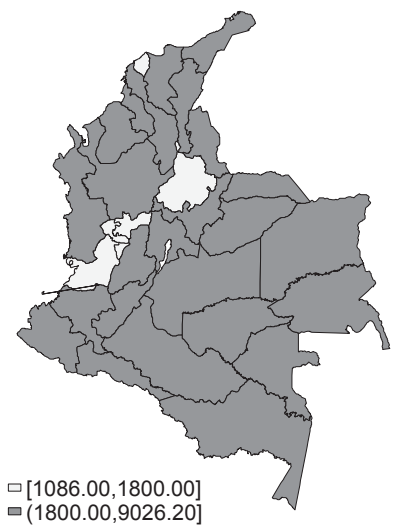

Colombia: Subsidized Regime, 2011

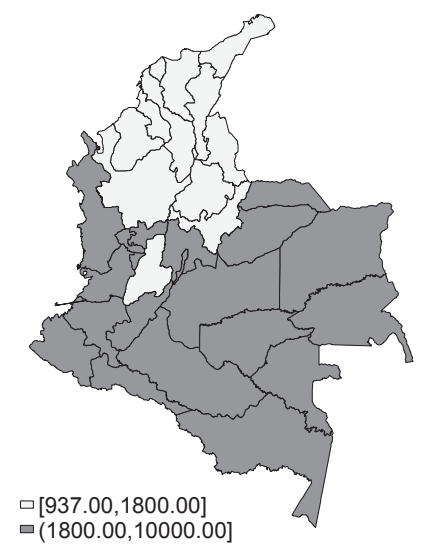

Fig. 1 - HHI Index by Market Area and Affiliation Regime. Source: Calculated by author with data from Ministry of Social Protection and Solidarity and Guarantee Fund, Fosyga.

Under the subsidized regime, the proportions are quite different but the trend is identical to that under the CR. On average, $40 \%$ of the market areas (13) did not exhibit high concentration 
between 2007 and 2011. However, while 45\% of the market areas were not concentrated in 2007, this percentage dropped to $36 \%$ in 2011. Comparatively, we observe a tendency toward more concentrated markets under the contributive regime than the subsidized regime, which is also reflected in the number of companies involved in each market.

The average number of insurance companies in the CR for the period considered in this study was 27 (with a minimum of 20 in 2011 and a high of 37 in 2009). The number of companies in this market has declined significantly, likely as a result of regulations on market entry and bankruptcies that have occurred in recent years. The average number of insurance companies in the subsidized regime was nearly twice that in the CR, 46, and exhibited relatively high variability over the period (a minimum of 42 in 2011 and a maximum of 48 in 2008).

A less concentrated market profile for the Contributory Regime is primarily observed in large areas or those with relatively large populations. It is the case of Bogotá, Valle del Cauca and Antioquia (in ascending order of concentration), that in 2007 , reached $39 \%$ of the country's population. However, market areas such as Caldas, Risaralda, Quindío and Tolima, which also had HHI values below 1800, had population sizes similar to those of Cauca, Cesar, Cordoba, Huila and Magdalena, where the markets were highly concentrated. Tolima, for example, which had $3.12 \%$ of the population in 2007, had a much lower concentration indicator than Cordoba, where had $3.4 \%$ of the population, and Cundinamarca, which the corresponding value is $5.36 \%$.

Throughout the period, the relatively more and less concentrated areas remain nearly constant. In 2011, the concentration map changes slightly, and markets such as Antioquia, Bolivar and Tolima are now among the most highly concentrated markets in the country. Even these market areas exhibit slight reductions in insurance coverage among the population compared to 2007 and 2008 .

The most concentrated market areas accounted for $68 \%$ of the country's population in 2007 , but these areas corresponded to $47 \%$ of the population in 2011. This is because important market areas such as Bogotá became concentrated in that year. Also noteworthy is that traditionally poor market areas, and therefore having more potential population for this regime, such as Chocó, Guainía, Guaviare, Putumayo and Vichada, remained among the more concentrated markets and, in some cases, doubled their concentration index values between 2007 and 2011.

This initial characterization verifies that the health insurance market is concentrated by market area, in both the CR and SR. Based on these concentration levels, we turn to an examination of the effect of market power on health insurance coverage.

All variables are transformed into logarithms, and we used two-stage least squares (2SLS) with fixed effects and robust standard errors to correct for potential heteroskedasticity. Two models are estimated: one for the CR and one for the SR. The variable of interest in both models is the measure of concentration calculated by the HHI indicator.

In both models, we used as instruments to predict the concentration level: the HHI with two lags and market size lagged by one period (both in logs). The first stage regression verified that the instruments were significant at $95 \%$ ( $\mathrm{p}$-value $<0.05$ ) with respect to explaining the concentration levels in the two markets, and in both cases the F-statistic exceeds the threshold of 10 proposed by Staiger and Stock (1997) for identifying weak instruments (F=39.54 for the CR, and 
$\mathrm{F}=54.66$ for the SR). Additionally, following Stock and Yogo (2005), we verified that the relative bias by 2SLS estimate is less than $10 \%$ of the bias by OLS estimates, and hence, the hypothesis of weak instruments is rejected.

The estimation results are presented in Table 2. Overall, they indicate that among the control variables, only the higher education coverage and first-level hospitals are significant in explaining the level of coverage under the CR, while first and second-level hospitals are important under the SR. The per-capita income by market area, although not significant in explaining the membership in the CR (contrary to expectations), is positively related to the coverage level in this regime and negatively (and significantly) associated with membership in the subsidized regime. This verifies some degree of emphasis on targeting of insurance coverage of individuals unable to pay in the SR and those who are able to pay in the CR. These results are similar to those obtained by Bates et al. (2010) in the case of private, individually purchased or employer-sponsored private insurance in the District of Columbia in the United States.

Tab. 2 - OLS and 2SLS estimates of affiliation and market concentration (second stage). Source: Calculated by author.

\begin{tabular}{|c|c|c|c|c|c|c|c|c|}
\hline \multirow{2}{*}{$\begin{array}{l}\text { Dependent } \\
\text { variable: }\end{array}$} & \multicolumn{4}{|c|}{ Log-Coverage_CR } & \multicolumn{4}{|c|}{ Log-Coverage_SR } \\
\hline & OLS & $\mathrm{EE}$ & 2SLS & $\mathrm{EE}$ & OLS & $\mathrm{EE}$ & 2SLS & $\mathrm{EE}$ \\
\hline $\log \mathrm{HHI}-\mathrm{CR}$ & $-0.9286^{* * *}$ & 0.0836 & $-0.966^{* * *}$ & 0.126 & & & & \\
\hline $\log$ HHI-SR & & & & & -0.003 & 0.04066 & -0.045 & 0.053 \\
\hline $\begin{array}{l}\text { log GDP } \\
\text { per-capita }\end{array}$ & -0.021 & 0.074 & 0.077 & 0.070 & -0.029 & 0.03742 & -0.030 & 0.035 \\
\hline $\begin{array}{l}\text { log propor- } \\
\text { tion of } \\
\text { children }\end{array}$ & -0.549 & 0.429 & -0.267 & 0.339 & 0.172 & 0.270 & 0.131 & 0.2515 \\
\hline $\begin{array}{l}\text { log propor- } \\
\text { tion of old } \\
\text { people }\end{array}$ & $-0.589^{*}$ & 0.247 & $-0.574^{* *}$ & 0.213 & -0.036 & 0.158 & -0.069 & 0.151 \\
\hline $\begin{array}{l}\text { log Num. } \\
\text { hospitals } \\
\text { level I }\end{array}$ & $0.226^{* * *}$ & 0.059 & $0.260^{* * *}$ & 0.042 & -0.066 & 0.037 & $-0.075^{*}$ & 0.034 \\
\hline $\begin{array}{l}\text { log Num. } \\
\text { hospitals } \\
\text { level II }\end{array}$ & & & & & $0.104^{* *}$ & 0.035 & $0.112^{* *}$ & 0.034 \\
\hline $\begin{array}{l}\text { log coverage } \\
\text { college }\end{array}$ & $0.197^{*}$ & 0.096 & $0.189^{*}$ & 0.090 & -0.044 & 0.055 & -0.047 & 0.055 \\
\hline constant & $13.762^{* * *}$ & 1.97 & $12.383^{* * *}$ & 1.708 & $4.727^{* * *}$ & 1.383 & $5.292^{* * *}$ & 1.351 \\
\hline F-test of IV & & & 39.54 & & & & 54.66 & \\
\hline $\mathrm{n}$ & 159 & & 159 & & 159 & & 159 & \\
\hline
\end{tabular}


Note: 1). Statistical significance $* \mathrm{p}<0.05,{ }^{* *} \mathrm{p}<0.01$, *** $\left.\mathrm{p}<0.001 .2\right)$ Estimates for 33 market areas during the period 2007-2011. 3) Estimates include time fixed effects and geographic market area. 4) Robust Standard errors -EE-corrected for potential heteroskedasticity. 5) log HHI of CR and SR instrumented with two lags of the respective concentration indicator and one lag of population size of the market area. 6) The instruments for both models were evaluated for redundancy and sub-identification of the instruments (Kleibergen-Paap $\mathrm{p}$-value $=0.000)$; weak identification test (Stock and Yogo, $\mathrm{p}$-value $=0.000)$; and test by inference robust in case of weak identification (Anderson and Rubin, p-value $=0.000$ ). From these we verified the importance of endogenous dependent variable and the identification of the instruments.

More relevant for the purposes of the present study is the analysis of the relationship between the HHI and coverage levels, indicating the exercise of market power or efficiencies associated with firm size. As shown in Table 2, the negative relationship is verified in both regimes, but it is significant only in CR. The estimated HHI coefficient in the membership model for CR, which represents the elasticity, suggests that a $10 \%$ increase in market concentration reduces insurance participation by $9.6 \%$. The significance and magnitude of the elasticity is even more disturbing when you consider that these results use the Department as the relevant geographic market and thus the estimated effects are likely conservative.

The empirical evidence suggests that health insurers possess and exercise market power in the contributory insurance market. Specifically, the findings indicate that an increase in the HHI for the insurance market results in fewer individuals obtaining health insurance, especially in areas with the most vulnerable populations. An interesting subject for future research is to establish the mechanism by which insurers act to discourage membership. Specifically, as obtaining an insurance policy is mandatory, the values of the premium and benefit package are defined by law, and insurers are not allowed to exclude individuals on the basis of pre-existing conditions, insurers may employ mechanisms to dissuade or prevent individuals from obtaining insurance coverage (barriers to entry, out of pocket spending, etc.).

However in Colombia, an EPS may be denied membership if the applicant cannot demonstrate ability to pay. Recent assessments of the sector have shown that EPS avoid membership of certain groups such as the self-employed, because they consider it as a type of population with little stability in premium and high spending. For some insurers, the self-employed or small firm worker is a person who often only joins to take care for a specific high cost health event. While this phenomenon has not been documented in depth, some reports of the "Defensoría del Pueblo" show that the denial of membership by transfer from another insurer, to be independent worker and disenrollment of beneficiaries are some of the most common complaints from health system users.

\section{DISCUSSION AND CONCLUSIONS}

The study finds that the insurance markets for contributory regime is concentrated and insurance companies exert market power in the health insurance market. This was demonstrated by the presence of an inverse relationship between the HHI concentration indicator and the number of insured individuals (insurance product coverage) by market area. Statistical evidence shows that the relationship between insurance market concentration and insurance coverage is not only negative, but is highly significant. This implies that even though the State tried to define the premium in order to ensure universal coverage, the results show that insurers are able to lev- 
erage their market power and the absence of effective regulation, to deny the membership to the population that is not attractive to the insurer. A legal intervention as the "Acción de Tutela" is being used by citizens to demand not only coverage services to people who are already members, but also the right to membership by non-members. But even the government is not clear whether the "Acción de Tutela" should be the tool to demand the right to membership. Part of the current reform debate that exists in the country, seeks to eliminate the enrollment process and ensure the right to provide services without going through an enrollment process for an insurer.

The health care reform established insurance as the strategy to ensure access; however the results of this research show that insurers have acted outlining their market. While regulations prohibit risk selection and insured exclusion, the trend in the market has shown that insurers have used their market power to affect the percentage of insured population as a way to keep a group of affiliated complying with maintaining financial stability of the insurer, in ensuring the regularity of premium. We can then forecast from this study that there is evidence that competition among insurers has played an important role in determining the terms of access for the population covered during the years 2007-2011. Given the particularities of health markets, social welfare issues must be decided from a second-best context, which implies that improvements in the health of a population depend on strong state regulation and intervention in these markets. Future research should focus on the development of measures that accurately capture product and firm characteristics in the health insurance market. This approach can be used to track market changes such as increases in integration or the increased use of private insurance.

\section{Acknowledgement}

This research was made possible thanks to financial support from Universidad del Norte and the Administrative Department of Science, Technology and Innovation -Colciencias- in Colombia. I appreciate the valuable comments of Francesc Trillas, Joan Rovira, Anna Matas and Jaume Puig-Junoy.

\section{References}

1. Arango, M., Restrepo, J., \& Casas, L. (2002). Estructura y conducta de la oferta del seguro de salud en Colombia. Lecturas de Economía, (56), 33-71.

2. Arrow, K. (1963). Uncertainty and the welfare economics of medical care. The American Economic Review, 53(5), 941-973. http://dx.doi.org/10.1215/03616878-26-5-851

3. Baker, L. (2001). Measuring competition in health care markets. Health Services Research, 36 (12), 223-251.

4. Baker, L., \& Corts, K. (1996). HMO Penetration and the cost of health care: Market discipline vs market segmentation, American Economic Review, 86(2), 389-394.

5. Bates, L.; Hilliard, J., \& Santerre, R. (2012). Do health insurers possess market power? Southern Economic Journal, 78(4), 1289-1304. http://dx.doi.org/10.4284/0038-4038-78.4.1289

6. Bolhaar, J., Lindeboom, M., \& van der Klaauw, B. (2010). Insurance search, switching behavior and the role of group contracts. Vrije Universiteit Amsterdam.

7. Bos, J. (2004). Does market power affect performance in the Dutch banking market? A comparison of reduced from market structure models. De Economist, 152(4), 491-512. http:// dx.doi.org/10.1007/s10645-004-2476-0 
8. Breyer, F., Bundorf, M., \& Pauly, M. (2012). Health insurance, health plans and risk variation. In: McGuire, T., Pauly, M., \& Pita Barros, P. (Eds.), Handbook of Health Economics, (pp. 123-456). Elsevier North-Holland, Amsterdam and London.

9. Dafny, B. (2010). Are health insurance markets competitive?. American Economic Review, 100(4), 1399-1431. http://dx.doi.org/10.1257/aer.100.4.1399

10. Dafny, L. (2008). Competition in health insurance markets. NBER Working Paper 14572. Cambridge, MA: National Bureau of Economic Research. Retrieved from: http://www. nber.org/papers/w14572

11. Dafny, L., Dranove, D.; Limbrock, F., \& Scott, F. (2011). Data impediments to empirical work on health insurance markets. B.E Journal of Economic Analysis \& Policy, 11(2), 2-22. http://dx.doi.org/10.2202/1935-1682.2822

12. Dafny, L., Duggan, M., \& Ramanarayanan (2011b). Paying a premium on your premium? Consolidation in the U.S health insurance industry. American Economic Review, 102(2), 11611185.

13. Demsetz, H. (1973). Industry structure, market rivalry, and public policy. Journal of Law and Economics, 16(1), 1-9. http://dx.doi.org/10.1086/466752

14. Dranove, D., Gron, A., \& Mazzeo, M. (2003). Differentiation and competition in HMO markets, The Journal of Industrial Economics, 51(4), 433-454. http://dx.doi.org/10.1111/j.00221821.2003.00209.x

15. Evans, W., Froeb, L., \& Werden, G. (1993). Endogeneity in the concentration-price relationship: causes consequences and cures. The Journal of Industrial Economics, 41(4), 431-438. http://dx.doi.org/10.2307/2950602

16. Frank, R., \& Lamiraud, K. (2009). Choice, price competition and complexity in markets for health insurance. Journal of Economic Behavior and Organization, 71(2), 550-562. http://dx.doi. org/10.1016/j.jebo.2009.04.005

17. Gaynor, M. (1994). Issues in the industrial organization of the market for physician services. Journal of Economics and Management Strategy, 3(1), 211-255. http://dx.doi.org/10.1111/ j.1430-9134.1994.00211.x

18. Gaynor, M., \& Town, R. (2011). Competition in health market. In: Pauly, M.; Mcguire, T. \& Barros, P. Handbook of Health Economics, 2( 9), 499-637.

19. Gaynor, M., \& Vogt, W. (2000). Antitrust and competition in health care markets, In: Culyer, A. \& Newhouse, Handbook of Health Economics, 1(B),1405-1487. http://dx.doi. org/10.1016/S1574-0064(00)80040-2

20. Kopit, W. (2004). Is there evidence that recent consolidation in the health insurance industry has adversely affected premiums?. Health Affairs, 23(6), 29-31. http://dx.doi. org $/ 10.1377 /$ hlthaff.23.6.29

21. Lamiraud, K., \& Frank, R. (2009). Choice, price competition and complexity in markets for health insurance. Journal of Economic Behavior \& Organization, 71(2), 550-562. http://dx.doi. org/10.1016/j.jebo.2009.04.005

22. Lustig, J. (2010). Measuring welfare losses from adverse selection and imperfect competition in privatized Medicare. Boston: Boston University. 
23. Maestas, N., Schoeder, M., \& Goldman, D. (2009). Price variation in markets with homogeneous goods: The case of medigap. (NBER Working Paper 14679). Cambridge, MA: National Bureau of Economic Research. http://dx.doi.org/10.3386/w14679

24. McLaughlin, C. (1987). HMO growth and hospital expenses and use: A simultaneousequation approach. Health Services Research, 22(2), 183-205.

25. McLaughlin, C., Merrill, J., \& Freed, A. (1984). The impact of HMO growth on hospital costs and utilization. In: Scheffler, R., \& Rossiter, L. (Eds). Advances in Health Economics and Health Services Research, (pp. 57-93). Greenwich, CY: JAI Press Inc.

26. Murray, M. (2006). Avoiding invalid instruments and coping with weak instruments. Journal of Economic Perspectives, 20(4), 111-132. http://dx.doi.org/10.1257/jep.20.4.111

27. Pauly, M. (1968). The economics of moral hazard: comment, American Economic Review, 58(3), 531-537.

28. Pauly, M., Hillman, A., Kim, M., \& Brown, D. (2002). Competitive behavior in the HMO marketplace. Health Affairs (Project Hope), 21(1), 194-202. http://dx.doi.org/10.1377/ hlthaff.21.1.194

29. Ramírez, J. (2006). Derechos de propiedad y desigualdades sociales en el sistema general de seguridad social colombiano. In: Leboniec, Y., \& Rodríguez, O. (Eds.), Colección de Estudios de Protección Social (pp. 439-79). Bogotá, CID: Universidad Nacional de Colombia.

30. Scanlon, D., Chernew, M., \& Lee, W. (2006). Competition in health insurance markets: limitations of current measures for policy analysis. Medical Care Research and Review, 63(6), 37S-55S. http://dx.doi.org/10.1177/1077558706293834

31. Schneider, J., Li, P., Klepser, D., Peterson, N., Brown, T., \& Scheffler, R.. (2008). The effect of physician and health plan market concentration on prices in commercial health insurance markets. International Journal of Health Care Finance and Economics, 8(1), 13-26. http:// dx.doi.org/10.1007/s10754-007-9029-4

32. Staiger, D., \& Stock, J. (1997). Instrumental variables regression with weak instruments. Econometrica, 65(3), 557-586. http://dx.doi.org/10.2307/2171753

33. Starc, A. (2010). Insurer pricing and consumer welfare: Evidence from Medigap. USA: Harvard University.

34. Stock J., \& Yogo M. (2005). Testing for Weak Instruments in Linear IV Regression. In: Andrews, D.W.K., Identification and Inference for Econometric Models (pp. 80-108). New York: Cambridge University Press.

35. Superintendence of Industry and Commerce. (2012). El mercado de aseguramiento en salud en Colombia. Serie Estudios de Mercado, 2012-I, Delegatura de la Protección de la Competencia, Colombia.

36. Town, R., \& Liu, S. (2003). The welfare impact of Medicare HMOs. RAND Journal of Economics, 34(4), 719-736.

37. Vásquez, J., \& Gómez, K. (2004). Selección adversa en el régimen contributivo de salud: el caso de la EPS de Susalud, Borradores del CIE, (10), Centro de Investigaciones Económicas, Universidad de Antioquia. 
Contact information

Rodriguez Sandra Acosta

Teacher-Researcher Instituto de Estudios Económicos del Caribe

Department of Economics, Universidad del Norte

Km 5 Via Puerto Colombia, Building D, Office: 2-26

Barranquilla-Colombia

Email:rsandra@uninorte.edu.co 